\title{
ANALISIS KINERJA TEKNOLOGI SLAM - GMAPPING UNTUK ROBOT BERODA MENGGUNAKAN SENSOR HOKUYO LASER SCANNER
}

\author{
Fatkhur Rohman ${ }^{1)}$, Winda Harsanti ${ }^{2}$ \\ ${ }^{1)}$ Dosen Program Studi Teknik Otomotif Elektronik Politeknik Negeri Malang \\ ${ }^{2)}$ Dosen Program Studi Manajemen Rekayasa Konstruksi Politeknik Negeri Malang \\ 1) fatkhur_rohman@polinema.ac.id \\ ${ }^{2)}$ win_harsanti@ rocketmail.com
}

\begin{abstract}
Abstrak
Permasalahan penting yang dihadapi oleh pengembang kendaraan otomatis adalah kemampuan untuk mendeteksi dan mengetahui jarak kendaraan terhadap lingkungan sekitar kendaraan pada saat beroperasi. Permasalahan lainnya adalah jarak halangan dan kendaraan tidak hanya pada satu arah/sudut saja, melainkan dalam semua sudut dalam radian 360 derajat. Permasalah tersebut dapat diselesaikan menggunakan algoritma lokalisasi dan pemetaan ruang. Sistem lokalisasi dan pemetaan ruang dalam bidang robotika dikenal dengan nama SLAM yang merupakan kepanjangan dari simultaneous localization and mapping. Tujuan dari penelitian ini untuk mendapatkan informasi peta halangan sekitar robot dan merepresentasikan data tersebut dalam simulasi 3D secara realtime di simulator Gazebo, Mendapatkan data sistem odometry menyangkut posisi akhir dan arah robot terakhir dari posisi awal keberangkatan secara realtime, Menerapkan algoritma SLAM GMapping pada platform embedded linux di robot 2 roda differential drive. Pengambilan data dilakukan dengan melakukan validasi hasil simulasi robot terhadap kondisi nyata halangan robot. Simulasi dilakukan melalui Simulaotr Gazebo yang langsung terhubung ke robot. Dari penelitian yang telah dilakukan bahwa algoritma program SLAM GMapping mampu secara simultan memetakan bentuk 2D bentuk halangan sekitar robot dan secara bersamaan memiliki informasi posisi akhir robor dari titik awal. Sensor Hokuyo 2D laser scanner sebagai input sensor mampu secara optimal mendeksi halangan yang diujikan dalam lingkungan ruang uji secara akurat dan realtime.
\end{abstract}

Kata Kunci: Simulator Gazebo, Sensor Laser Scanner, Robot 2 Roda, dan SLAM GMapping.

\section{PENDAHULUAN}

Permasalahan penting yang dihadapi oleh pengembang kendaraan otomatis adalah kemampuan untuk mendeteksi dan mengetahui jarak kendaraan terhadap lingkungan sekitar kendaraan pada saat beroperasi. Permasalahan yang kedua adalah status posisi terakhir yang menyangkut jarak tempuh dan posisi arah kendaraan terakhir dari titik awal. Permasalahan ini juga dikenal dengan sistem odometry kendaraan. Permasalah tersebut dapat diselesaikan menggunakan algoritma lokalisasi dan pemetaan ruang. Sistem lokalisasi dan pemetaan ruang dalam bidang robotika dikenal dengan nama SLAM yang merupakan kepanjangan dari simultaneous localization and mapping. Penelitian ini menggunakan sebuah sensor 2D Hokuyo laser scanner yang umumnya digunakan pada perangkat pesawat UAV quad copter. Sensor lainnya adalah 2 rotary encoder sebagai masukan informasi sistem odometry kendaraan dan sensor IMU. Penelitian sebelumnya telah dilakukan oleh Lamon, Kolski dan Siegwart dari Zurich, menggunakan sebuah kendaraan konvensional yang telah dimodifikasi dengan menambahkan sistem drive by wire dan 4 sensor standar kendaraan autonomous yang terdiri dari 5 sensor laser scanner, GPS, IMU, Streaming Camera, Gyroscope dan 4 unit personal computer. Penelitian tersebut menghasilkan monitoring lokalisasi, navigasi autonomuous dan 3D mapping yang akurat. Penelitian ini memiliki unjuk kerja yang sangat akurat dikarenakan 
menggunakan 5 sensor laser scanner dan banyak sensor tambahan lain. Namun, hal ini tidaklah murah mengingat 1 sensor SICK laser memiliki harga sangat mahal sehingga tidak mudah diterapkan pada kendaraan autonomuous. Pajaziri dan Avdullahu menerapkan algoritma gmapping slam pada simulator robot turtlebot di simulator rviz pada lingkungan buatan simulator. Penelitian tersebut berhasil mengendalikan robot turtlebot secara autonomous pada lingkungan simulator rviz memanfaatkan lingkungan buatan pada simulator. Semua tahap penelitian juga dilakukan memanfaatkan framework Robot Operating System dan package software open source SLAM Gmapping. Pajaziri dkk belum mampu menerapkan algoritma SLAM GMapping pada kendaraan autonomuous nyata dan lingkungan navigasi pun hanya terbatas pada simulator RVIZ. Penelitian ini bertujuan untuk menerapkan algoritma SLAM GMapping pada perangkat keras embedded system di sebuah robot beroda, lalu mensimulasikan kinerjanya dalam bentuk peta ruang dan menentukan posisi terbaru robot beroda terhadap titik mulai awal keberangkatan. Hasil akhir dari penelitian adalah sebuah robot otomatis yang mampu menyediakan informasi halangan sekitar dan status posisi terakhir kendaraan dari titik awal keberangkatan dan melakukan keputusan manuver secara mandiri. Sistem informasi kendaraan otomatis tersebut bisa dipantau secara langsung lewat dashboard laptop operator dari jarak jauh memanfatkan jaringan lokal intranet. Simulasi robot beroda dibuat serupa dengan kondisi nyata lingkungan robot menggunakan simulator open source GazeboSim.

SLAM adalah sebuah solusi yang biasa digunakan dalam dunia robotika untuk menjawab masalah pembentukan peta ruang dari sebuah lingkungan robot yang sedang bergerak yang mana pada saat yang bersamaan melakukan proses navigasi dari peta yang telah dihasilkan. SLAM sendiri merupakan singkatan dari Simultanious Localization and Mapping. Pada awal mulanya, teknologi SLAM diperkenalkan oleh Hugh Durrant-Whyte dan John J. Leopard. Slam sendiri sebenarnya bukanlah sebuah algoritma tunggal seperti PID, Fuzzy atau sejenisnya melainkan sebuah konsep yang terdiri dari banyak tahapan untuk merealisasikan tujuan yang diinginkan. Teknologi ini seringkali digunakan untuk aplikasi 2D dan 3D dan pada tahap lanjut digunakan dalam aplikasi self driving cars, unmanned aerial vehicle, autonomuous underwater vehicle, planetary rovers. Terdapat 2 perangkat utama yang menjadi prasarat untuk menggunkan algoritma SLAM yaitu:

1) Sistem Odometry

Untuk mengetahui posisi aktual robot dari posisi awal keberangkatan. Hal ini dapat dilakukan dengan berbagai macam sensor yang disesuikan dengan kebutuhan pose, arah, altitude atau hanya berasal dari sensor putaran roda.

2) Jarak Halangan Sekitar

3) Dapat disediakan oleh sensor laser scanner yang banyak tersedia. Sensor laser scanner bisa mendeteksi sampai ratusan meter yang bisa disesuiakan dengan tujuan proses mapping.

Sinar laser terbuat dari cahaya yang semuanya terdiri dari panjang gelombang yang sama. Berkas cahaya dalam cahaya biasa mengalir ke arah yang berbeda. Sinar laser bergerak dalam arah yang sama persis. Sinar laser tidak menyebar dan tidak melemah (Zebua, 2011). Laser (singkatan dari bahasa Inggris: Light Amplification by Stimulated Emission of Radiation) merupakan mekanisme suatu alat yang memancarkan radiasi elektromagnetik, biasanya dalam bentuk cahaya yang tidak dapat dilihat maupun dapat lihat dengan mata normal, melalui 
proses pancaran terstimulasi. Pancaran laser biasanya tunggal, memancarkan foton dalam pancaran koheren (Minarni dan Gita, 2013).

Laser Laser scanner merupakan alat yang digunakan untuk mengetahui jarak permukaan suatu obyek dengan menghitung waktu tempuh pulang - pergi dari suatu pulsa cahaya. Satu pulsa cahaya digunakan untuk mengukur satu jarak dari waktu tempuhnya dari mulai dipancarkannya suatu pulsa hingga mengenai obyek, kemudian diterima kembali pulsanya menggunakan detector, karena cepat rambat cahaya (c) telah diketaui dan waktu tempuh cahaya tersebut dari mulai dipancarkan sampai diterima kembali oleh sensor diketaui sensor sehingga didapatkan rumus (Vidyan, et al, 2013):

$$
d=\frac{1}{2} \times c \times \Delta t
$$

Keterangan :

$\mathrm{d}=$ Jarak dari alat ke obyek (meter)

$\mathrm{c}=$ Cepat rambat gelombang (meter/second)

Delta $\mathrm{t}=$ Waktu tempuh $($ Second $)$

\section{METODOLOGI PENELITIAN}

Tahapan yang dilakukan di dalam penelitian ini dibagi menjadi 4 (empat) bagian utama yaitu studi literatur, penyediaan komponen dan perangkat keras, pembuatan model 3D simulator, pembuatan program simulator dan komunikasi simulator terhadap hardware dan penulisan laporan. Tahap pertama adalah studi literatur yang dilakukan dari beberapa sumber buku dan internet terhadap materi :

a) Prinsip kerja algoritma SLAM GMapping

b) Desain 3D Robot pada Simulator Gazebosim

c) Komunikasi robot beroda dan simulator Gazebosim

d) Setup jaringan lokal untuk monitoring/dashboard robot dari laptop secara wireless

Tahap selanjutnya adalah menyiapkan komponen dan perangkat keras yang digunakan dalam penelitian. Untuk robot beroda sendiri memanfaatkan robot beroda yang ada pada Laboratorium Robotika, Jurusan Teknik Elektronika, Politeknik Negeri Malang, dengan menambahkan kontroler utama sebuah perangkat embedded system Odroid XU4, USB wifi adapter, kamera dan sebuah sensor Hokuyo Laser Scanner.

Tahap ketiga yaitu membuat desain robot 3D menggunakan sintak Bahasa XML dalam extensi xacro yang bisa dikonversi menjadi sdf file dan dimuatkan pada simulator 3D Gazebosim. File model robot menggunakan format xml dalam ekstensi .xacro, yang mana menginformasikan dimensi, warna, inertia dan nilai friction yang disesuikan dengan robot asli. Setelah model robot berhasil berjalan dalam lingkungan simulator, maka tahap selanjutnya adalah mendesain kontroler differential drive dan sensor robot beroda, hal ini meliputi kontrol kecepatan dan arah motor DC, pembacaan sensor rotary encoder dan laser scanner. Tahap yang terakhir adalah komunikasi robot dengan laptop(sebagai dashboard) memanfaatkan jaringan wifi dengan pusat sebuah akses point yang dibentuk dalam sebuah jaringan lokal.

Untuk tujuan pengambilan data Gambar berikut menunjukkan perencanaan blok diagram untuk penelitian ini.

Pengambilan data dilakukan dengan melakukan validasi hasil simulasi robot 
terhadap kondisi nyata halangan robot. Simulasi dilakukan melalui GazeboSim yang langsung terhubung ke robot. Halangan nyata robot ditampikan dalam bentuk peta ruang dan status pose/arah robot sama dengan kondisi asli terakhir robot. Kontrol robot dilakukan dari titik klik disimulator atau kontrol manual dari joystick user.

Untuk tujuan pengambilan data Gambar berikut menunjukkan perencanaan blok diagram untuk penelitian ini.

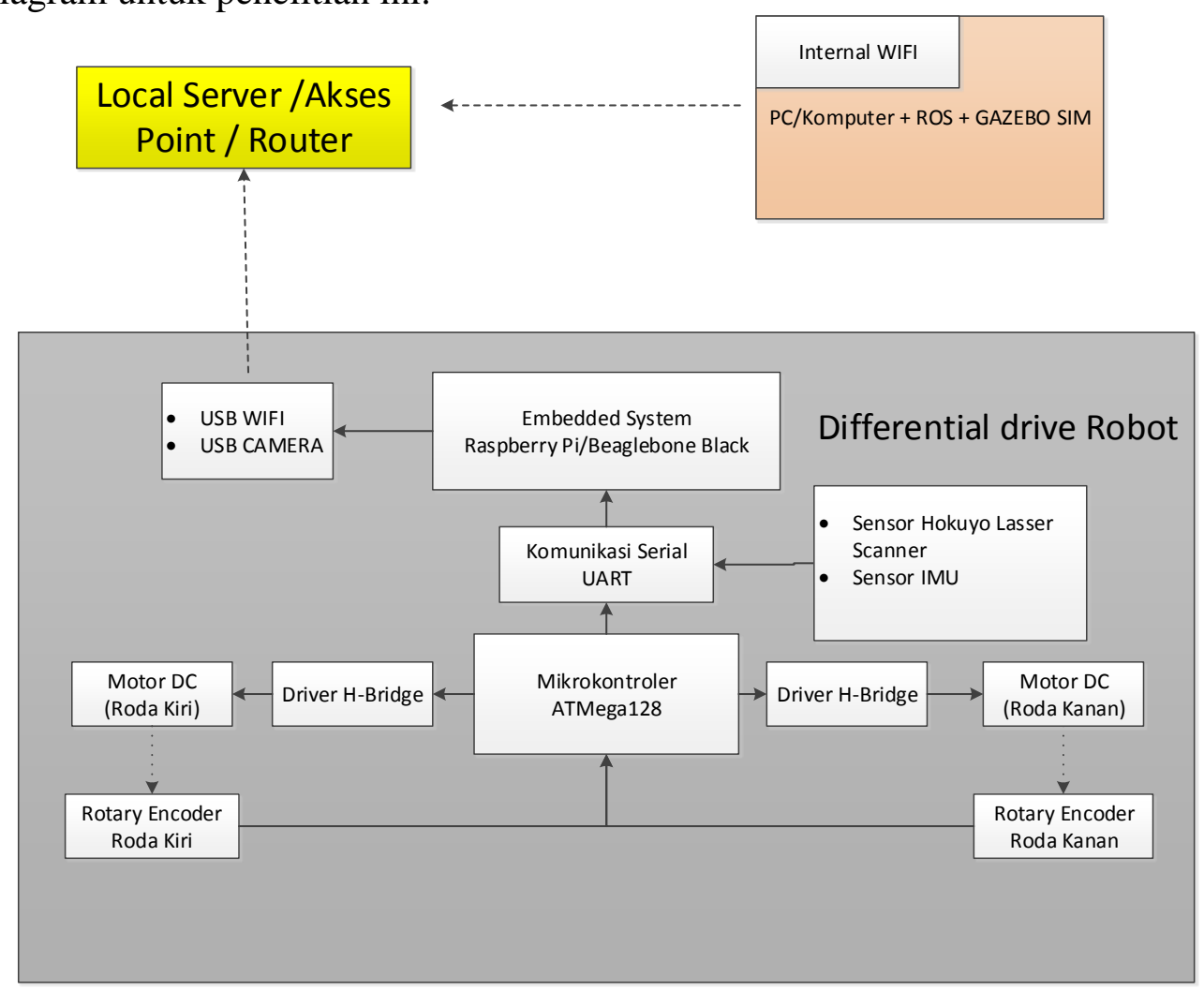

Gambar 1. Blok Diagram Alat

\section{HASIL DAN PEMBAHSASAN}

Berikut adalah hasil penelitian yang diambil.
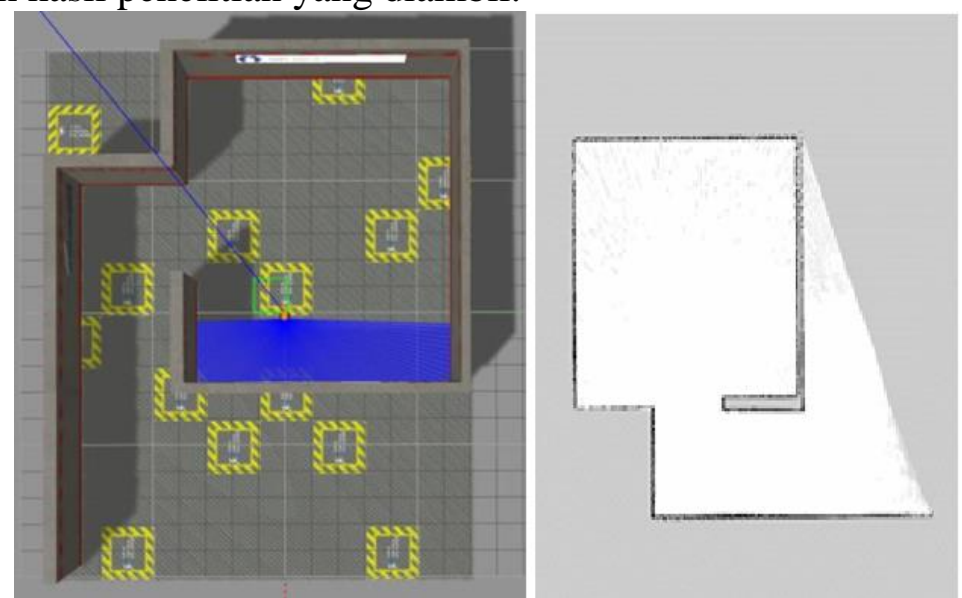

Gambar 2. Data Uji 1, Ruang Asli dan Hasil Simulasi 


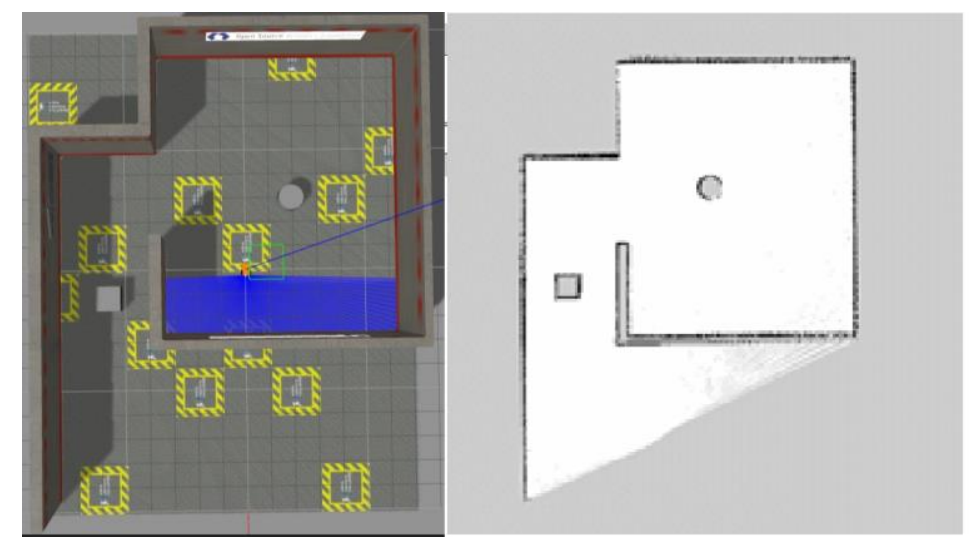

Gambar 3. Data Uji 2, Ruang Asli dan Hasil Simulasi

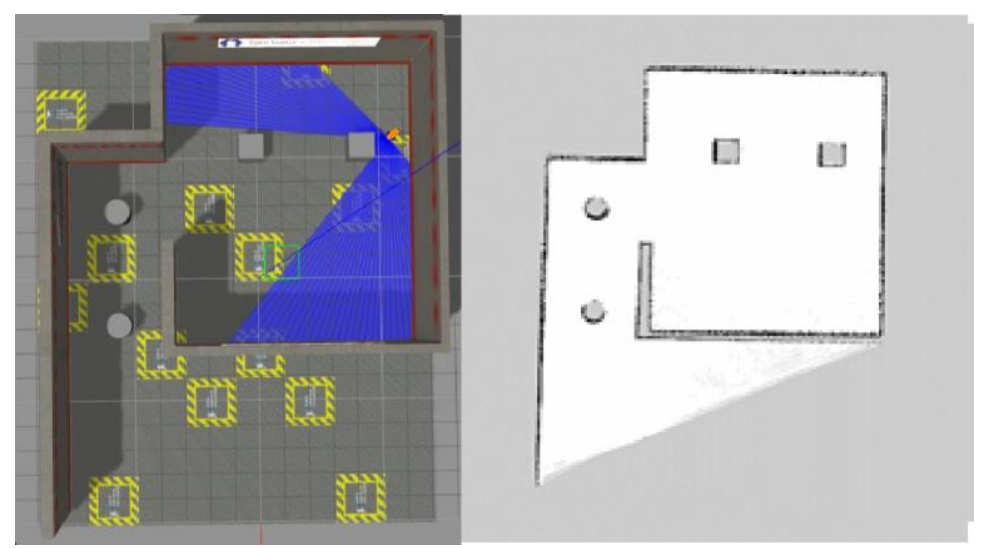

Gambar 4. Data Uji 2, Ruang Asli dan Hasil Simulasi

Dari hasil penelitian diatas terlihat bahwa terdapat satu ruangan yang mana memiliki lokasi dan jarak halangan yang berbeda. Robot beroda mampu menggunakan sensor hokuyo laser scanner sebagai input pembacaan halangan sekitar dengan sudut 270 derajat. Sensor rotary juga mampu bekerja untuk mengupdate informasi odometry robot.

\section{KESIMPULAN}

Dari penelitian yang telah dilakukan didapatkan kesimpulan bahwa:

1) Pemetaan halangan ruangan bisa secara akurat dibuat secara realtime menggunakan sensor Hokuyo laser scanner.

2) Algoritma SLAM GMapping dapat diterapkan pada aplikasi cerdas sehingga sebuah robot/kendaraan listrik mampu mengetahui peta halangan sekitar dan informasi odometry dari titik awal..

\section{DAFTAR PUSTAKA}

Basori, Slamet. 2014. "Implementasi Odometry pada robot otomatis kontes robot abu Robocon Indonesia". Malang.

Lamon, Stachniss, Triebel, Pfaff. 2017. "Mapping with an Autonomous Car", Zurich-Switzerland. Research Gate.

Olson, Edwin. 2004. "A Primer on Odometry and Motor Control".Electronic Group Discuss. 
PENA TEKNIK: Jurnal Ilmiah Ilmu-Ilmu Teknik

Volume 3, Nomor 1, Maret 2018: $67-72$

Pajaziti, Avdullahu. 2014 "SLAM- Map Building dan Navigation via ROS", IJISAE: 2147-6799.

Surmann, Lingemann, Hertzberg. "A 3D Laser Range Finder for autonomous mobile robot". International Symposium on Robotics. 